\title{
Knowledge, attitudes and practices of neonatal staff concerning neonatal pain management
}

\begin{tabular}{|c|c|}
\hline \multicolumn{2}{|c|}{$\begin{array}{l}\text { Authors: } \\
\text { Sizakele L.T. Khoza }{ }^{1} \\
\text { A.A. Tjale }\end{array}$} \\
\hline \multicolumn{2}{|c|}{$\begin{array}{l}\text { Affiliations: } \\
{ }^{1} \text { Department of Nursing } \\
\text { Education, Faculty of Health } \\
\text { Sciences, University of the } \\
\text { Witwatersrand, South Africa }\end{array}$} \\
\hline \multicolumn{2}{|c|}{$\begin{array}{l}{ }^{2} \text { Child Nurse Consultant, } \\
\text { South Africa }\end{array}$} \\
\hline \multicolumn{2}{|c|}{$\begin{array}{l}\text { Correspondence to: } \\
\text { Sizakele Khoza }\end{array}$} \\
\hline \multicolumn{2}{|c|}{$\begin{array}{l}\text { Email: } \\
\text { siza.khoza@wits.ac.za }\end{array}$} \\
\hline \multicolumn{2}{|c|}{$\begin{array}{l}\text { Postal address: } \\
1 \text { Jan Smuts Avenue, } \\
\text { Braamfontein, Johannesburg } \\
2000 \text {, South Africa }\end{array}$} \\
\hline \multicolumn{2}{|c|}{$\begin{array}{l}\text { Dates: } \\
\text { Received: } 29 \text { Oct. } 2013 \\
\text { Accepted: } 30 \text { Sept. } 2014 \\
\text { Published: } 28 \text { Nov. } 2014\end{array}$} \\
\hline \multicolumn{2}{|c|}{$\begin{array}{l}\text { How to cite this article: } \\
\text { Khoza, S.L.T. \& Tjale, A.A., } \\
2014, \text { 'Knowledge, attitudes } \\
\text { and practices of neonatal } \\
\text { staff concerning neonatal } \\
\text { pain management', Curationis } \\
\text { 37(2), Art. \#1246, } 9 \text { page. } \\
\text { http://dx.doi.org/10.4102/ } \\
\text { curationis.v37i1.1246 }\end{array}$} \\
\hline \multicolumn{2}{|c|}{$\begin{array}{l}\text { Copyright: } \\
\text { C 2014. The Authors. } \\
\text { Licensee: AOSIS } \\
\text { OpenJournals. This work is } \\
\text { licensed under the Creative } \\
\text { Commons Attribution } \\
\text { License. }\end{array}$} \\
\hline \multicolumn{2}{|l|}{ Read online: } \\
\hline 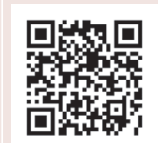 & $\begin{array}{l}\text { Scan this QR } \\
\text { code with your } \\
\text { smart phone or } \\
\text { mobile device } \\
\text { to read online. }\end{array}$ \\
\hline
\end{tabular}

Background: Neonatal pain management has received increasing attention over the past four decades. Research into the effects of neonatal pain emphasises the professional, ethical and moral obligations of staff to manage pain for positive patient outcomes. However, evaluation studies continuously report evidence of inadequate neonate pain management and a gap between theory and practice.

Objective: This study reviewed current practice in neonatal pain management to describe the knowledge, attitudes and practices of nurses and doctors regarding pain management for neonates in two academic hospitals.

Method: A non-experimental, prospective quantitative survey, the modified Infant Pain Questionnaire, was used to collect data from 150 nurses and doctors working in the neonatal wards of two academic hospitals in central Gauteng.

Results: The response rate was 35.33\% $(n=53)$, most respondents being professional nurses $(88.68 \% ; n=47)$ working in neonatal intensive care units $(80.77 \% ; n=42) ; 24(45.28 \%)$ had less than 5 years' and 29 respondents 6 or more years' working experience in neonatal care. A review of pain management in the study setting indicated a preference for pharmacological interventions to relieve moderate to severe pain. An association $(p<0.05)$ was found between pain ratings on 5 procedures and frequency of administration of pharmacological pain management. Two-thirds of respondents $(64 \%)$ reported that there were no pain management guidelines in the neonatal wards in which they worked.

Conclusion: The interventions to manage moderate neonatal pain are in line with international guidelines. However, neonatal pain management may not occur systematically based on prior assessment of neonatal pain, choice of most appropriate intervention and evaluation. This study recommends implementation of a guideline to standardise practice and ensure consistent and adequate pain management in neonates.

\section{Introduction}

In the era of humanitarianism, the issue of human rights demands attention, across the spectrum of life ranging from the unborn child to the dying elderly patient. Holistic nursing care should provide compassionate care and focused interventions that bring comfort to the patient (Kolchaba 1995). Clinical procedures almost always cause the neonate distress and require specific comfort strategies. Advances in health technology and increased survival of neonatal patients in the past four decades have seen a renewed interest in the topic of neonatal pain and its management. This survival is accompanied by various clinical procedures that form part of neonatal health care, such as endotracheal intubation to initiate and maintain ventilator support, insertion of an intravenous catheter to administer fluids or medication, and heel pricks to obtain blood specimens for investigations. These clinical procedures induce pain and require pain management (Anand \& Hall 2008; Belliene et al. 2009).

Pain is considered to have protective functions. Existing evidence confirms, however, that untreated or ineffectively treated pain has both short- and long-term negative effects on the health of the neonate. Amongst these are development of complications such as intracranial haemorrhage, decreased immune response, delayed weight gain, prolonged hospitalisation, impaired neonate-parent bonding, and development of psychosomatic conditions such as hyperalgesia and allodynia (Granau, Holsti \& Peters 2006; Sharek et al. 2006; Abdulkader et al. 2008). In contrast, effective pain management in neonates has been shown to increase positive patient outcomes, as evidenced by a decrease in length of stay in hospital as a result of patients experiencing fewer complications, fewer incidences of infections and consistent weight gain (Walker \& Howard 2002; Ballweg 2007; Urso 2007). In the light of this information neonatal pain 
management becomes an ethical and moral obligation for all neonatal staff, nurses and doctors alike.

According to best practice clinical guidelines, effective neonatal pain management begins with the assessment of neonates' pain in order to implement the appropriate intervention to relieve or treat pain adequately (Lago et al. 2009; Spence et al. 2010).

\section{Problem statement}

This study was motivated by the researcher's ten years of clinical practice observing neonatal pain management without the aid of a guideline. In the absence of a guideline, assessment of infant pain appeared to be an intuitive exercise based on individual healthcare practitioners' identification and interpretation of the infant's signs of pain. Similarly, pain management or pain relief interventions were largely pharmacological and subject to the prescriber's knowledge of and experience with available analgesics.

The fast-paced nature of a neonatal intensive care unit (NICU) is largely focused on restoring and maintaining the lives of high-risk, critically ill neonates. As a result pain appeared to be the last priority, receiving little or no attention. The researcher's search for possible reasons for this generated anecdotal evidence suggesting that neonatal staff are not convinced of the significance of neonatal pain, and hence do not support pain management as a priority need. This raised the question as to whether neonatal pain was adequately assessed and managed in this setting, and gave rise to the following research question: What are the knowledge, attitudes and beliefs of neonatal staff concerning neonatal pain management?

\section{Research objectives}

The objectives of this study were to: explore current neonatal pain management strategies; describe the knowledge of neonatal staff on neonatal pain; and examine the attitudes and beliefs of neonatal staff regarding neonatal pain.

\section{Definition of key concepts}

The following terms used consistently throughout the report were defined within the context of the study:

- Neonatal procedural pain: Includes acute and chronic pain induced and experienced as a result of named procedures (Porter et al. 1997; Simons et al. 2003; Dodds 2003; Carbajal et al. 2008).

- Neonatal staff: Collective term for nurses and doctors working in neonatal wards.

- Pharmacological interventions: Schedule 4-7 drugs inclusive of sedatives, muscle relaxants, anaesthetic agents, narcotic analgesics and non-steroidal antiinflammatory agents.

- Non-pharmacological interventions: Behavioural actions to minimise, reduce or relieve painful stimuli, limited to oral sucrose, swaddling, non-nutritive sucking, breastfeeding and kangaroo mother care.

- Beliefs: Personal opinions regarding facts as being true or right, with or without formal knowledge or proof (Porter et al. 1997; Andersen et al. 2007; Bellini \& Damato 2009).

- Attitude: Behaviour influenced by opinion (McLaughlin et al. 1993; Porter et al. 1997; Dodds 2003; Andersen, Greve-Isdahl \& Jylli 2007; Bellini \& Damato 2009).

- Knowledge: Formal or informal education guiding practice (McLaughlin et al. 1993; Porter et al. 1997; Andersen et al. 2007; Bellini \& Damato 2009).

\section{Contribution to the field}

An inventory of the common neonatal pain management strategies currently utilised may provide a means to render holistic care for pain as a priority of care for neonates. It is envisaged that an understanding of the knowledge, attitudes and beliefs influencing neonatal pain management will add to the body of knowledge in this area. Empirical data generated in this study may serve to increase the awareness of and priority awarded to this need. It is further hoped that this study may encourage collaborative development of a best practice clinical guideline to optimise neonatal pain management.

\section{Literature review}

The International Association for the Study of Pain defines pain 'as an unpleasant sensory and emotional experience associated with actual or potential tissue damage, or described in terms of such damage' (Merskey et al. 1979:250). Interpretation and experience of pain is subjective, based on an internal construct of pain through the encountered injury, as reported by the person suffering from the pain (Ballweg 2007). The American Academy of Pediatrics and Canadian Paediatric Society (2000) acknowledge that this may limit the neonates' ability to conform to this definition of pain, as neonates do not have the conventional verbal means to report pain and depend on neonatal staff to assess, recognise, diagnose and manage their pain. In order to do so, neonatal staff need to have special knowledge and understanding of neonatal physiological and behavioural responses to pain and relevant interventions to relieve pain. Knowledge and understanding of neonatal pain begins with awareness that neonates do indeed experience pain.

The neonates' experience of pain has been investigated extensively over the last five decades, and confirms empirical evidence on their ability to perceive, process, respond to and recall pain (Anand \& Hickey 1987; Fitzgerald \& Anand 1993; Johnston et al. 1995; Anand et al. 1999). Johnston et al. (1995) established that neonates perceive pain based on nociception developed in utero before the age of 24 weeks. The perceived pain stimulus is transmitted slowly from the periphery to the brain over non-myelinated nerve fibres before the age of 30 weeks and faster over myelinated nerve fibres beyond 30 weeks' 
gestation (Anand \& Hickey 1987; Fitzgerald \& Anand 1993; Johnston et al. 1995; Evan 2001). These studies found that the nociceptive sensation was widely distributed in the brain in the absence of an identifiable 'brain centre' and initiated the release of catecholamines and cortisol, resulting in a variety of physiological responses to pain, for example tachycardia, tachypnoea, desaturation, hypertension and hyperglycaemia. In addition, neonatal patients below 25 weeks' gestation displayed inability to differentiate between touch and pain stimuli. Hummel and Puchalski (2001) linked this to the close proximity of the neonates' pain and touch receptors. Based on the neuroanatomy and neurophysiology of neonates, Ballweg (2007) concluded that unavailability of descending inhibitory neurotransmitters to modulate pain meant that neonatal patients experienced pain more intensely than adults or paediatric patients.

Anand and the International Evidence-Based Group for Neonatal Pain (2001:174) state that 'if a procedure is painful in adults, it should be considered painful to neonates'; the expression of pain may differ from that of an adult, however. 'Pain assessment in neonates should be comprehensive and multidimensional, including contextual, behavioural and physiological indicators' (Anand and International EvidenceBased Group for Neonatal Pain 2001:175), which requires that the neonate's caregiver be aware, knowledgeable, vigilant and responsive to ensure that pain management is multilevel and multimodal.

Empirical evidence of neonatal pain and its management has been shown to have little impact on clinical practice (McLaughlin et al. 1993; Porter et al. 1997; Rouzan 2001; Andersen et al. 2007; Gradin \& Eriksson 2010). In fact, neonatal patients still experience pain as a result of ineffective pain management (Anand \& Hall 2008). This has been attributed to the staff's lack of appropriate knowledge of neonatal pain. These studies identified staff attitudes and beliefs concerning pain and fear of the effects of analgesia as factors contributing to inadequate pain management in neonates.

To bridge the gap between knowledge and practice, national and international collaborations formed to develop research-based best practice clinical guidelines to inform effective neonatal pain management (Anand \& International Evidence-Based Group for Neonatal Pain 2001; Anand et al. 2004; Carbajal et al. 2008; Gradin \& Eriksson 2010). Designed to support decisionmaking in patient care, these guidelines enable neonatal staff to advocate for and provide scientifically approved interventions to assess, diagnose, prevent, alleviate and treat neonatal pain. The content is instrumental in the continued education and training of all neonatal caregivers, including nursing, medical and pharmaceutical staff as well as parents on neonatal pain management (McKechnie \& Levene 2008). The desired outcome would be standardised and consistent pain management resulting in quality care of the neonate.

Despite the value of clinical guidelines in the literature, the apparent absence of clinical guidelines presented a dearth in knowledge concerning neonatal pain management in Gauteng hospitals. As a starting point this study sought to describe the knowledge, attitudes and beliefs of neonatal staff on pain management in Gauteng hospitals.

\section{Research method and design Research approach}

A quantitative, descriptive, cross-sectional survey was used to describe the broader practice of pain management in neonatal wards. According to LoBiondo-Wood and Haber (2006), a survey allows for the collection of accurate, detailed descriptions of existing variables (knowledge, beliefs and attitudes) and the use of the generated data to justify and assess current practice (neonatal pain management) to plan for implementation of improved forms of healthcare practice.

\section{Context of the study}

The neonatal wards of two of the public academic hospitals in Gauteng, South Africa, were selected for this study as they offer a full range of tertiary, secondary and specialised services in neonatal care. The combined bed capacity of the 2 facilities is 20 in the intensive care ward and 60 in the highcare wards. Critically ill neonates requiring mechanical ventilation support and those who require intensive care as a result of congenital and developmental health problems are admitted to the NICU. The high-care units admit infants requiring intensive care without mechanical ventilator support, that is following extubation, with medical symptoms under control. On average 1200 infants are admitted into these wards each month.

Demand for tertiary and specialist care is high at academic hospitals. As part of routine health care these neonatal patients are subjected to a number of the clinical procedures identified in the data collection instrument.

\section{Population and sampling}

At the time of the study the total number of medical and nursing staff working in the neonatal wards of the selected academic hospitals was 168 . To obtain a confidence level of $95 \%$ it was calculated that a sample size comprising of 153 respondents for the self-administered questionnaire was required. In order to realise this sample size the researcher targeted the entire population of neonatal staff readily available in the wards.

Neonatal staff in the wards includes registered nurses who coordinate patient care, perform clinical skills and have administrative duties related to patient care. The medical doctors teach and carry a clinical responsibility; they hold joint posts in the Government and universities associated with academic hospitals. Senior undergraduate medical and nursing students are allocated to these wards to learn specialised skills pertaining to the care of critically ill neonates. These hospitals also provide the clinical setting 
for the advanced education and training of postgraduate students specialising in neonatal care.

Neonatal staff (nurses and medical doctors) with more than 3 weeks of working experience in the NICU or high-care wards were included in this study. This included postgraduate students allocated to these wards for experiential learning.

\section{Data collection}

Data collection for this study was over a four-month period in 2010. The data collection instrument used in this study was adapted from the Infant Pain Questionnaire developed by Porter et al. (1997), who first used this questionnaire to collect data in their study entitled 'Pain and pain management in newborn infants' (1997). An open-ended question from the study by Dodds (2003) exploring the aspects of neonatal procedural pain, its assessment and management was included to investigate respondents' opinions on neonatal pain, as this was not part of the Infant Pain Questionnaire.

In order to review current neonatal pain management practice in the chosen settings the researcher added three questions based on the literature review on pain management interventions. The questionnaire had two sections, each designed to elicit information related to the objectives of this study.

Section A of the modified Infant Pain Questionnaire consisted of four subscales focusing on the respondents' demographic characteristics. These data established population characteristics and allowed for conducting comparative data analysis.

Section B of the questionnaire consisted of 13 items. Questions 1-5 had nominal responses to elicit the respondents' knowledge, beliefs and attitudes concerning neonatal pain. The questions required the respondents to indicate whether they had experienced procedure- related pain in neonates, to give an opinion of neonatal pain, compare the intensity of neonatal pain to adult pain, and indicate whether their unit had a written neonatal pain guideline. Questions 6-10 were on a five-point Likerttype scale, the design of which is useful in measuring respondents' opinions or attitudes on a subject (Burns \& Grove 2005; Maree 2009). In this section of the survey the respondents rated the intensity of the pain associated with the 10 identified clinical procedures, and reported frequency of pain management interventions, actual or believed. Each response category was assigned a numerical value in ascending order from 0 to 4 , with 0 being the most negative and 4 the most positive. The last 3 items (Questions 11-13) required the respondents to indicate the different types of pharmacological or non-pharmacological pain management interventions implemented prior to, during and after the identified clinical procedures.

During the data collection period the researcher handdelivered information letters and questionnaires to the neonatal wards. The information letter included a brief explanation of the study to prospective respondents. The shift leaders assisted in distributing the information letters and questionnaires to colleagues not yet on duty. To accommodate the work schedules of the neonatal staff the researcher visited the wards at the beginning of the shift prior to handover or after the first care routine was completed. The respondents were asked to drop the completed questionnaire in a box that was left in the wards, by the end of their shift (10-12 hours later). The researcher emptied the box at the end of each shift.

On completion of data collection a sample subset of the questionnaires was extracted and the Cronbach alpha ( $)$ coefficient calculated to measure reliability of this study. The range was found to be between 0.72 and $0.92(\alpha<1)$, indicating that the instrument has good reliability. This was consistent with Cronbach $\alpha$ coefficients calculated for the Infant Pain Questionnaire by Porter et al. (1997) and Andersen et al. (2007) ranging from 0.74 to 0.93 .

\section{Data analysis}

In total 53 questionnaires were completed; these were coded according to the collection site using the abbreviations of the hospital and numbered from 1 to 53. All of the raw data were manually captured onto a Microsoft Excel spreadsheet and then entered on the computer statistical package Stata 11 for analysis. Data collected from the closed-question items were analysed in a progressive order to obtain descriptive statistics of the respondents' demographic data, followed by analysis of the findings on their knowledge, beliefs and attitudes on infant pain and its management. Most of the measurement of data collected was nominal and ordinal.

The calculated comparative statistics explain the association and strength of the relationship between the study variables, namely the knowledge of neonatal procedural pain and pain management interventions, beliefs about neonatal procedural pain and attitudes towards neonatal procedural pain and pain management interventions. To facilitate item analysis some of the data categories were collapsed prior to calculating comparative statistics. The main statistical tests employed in this study were Fischer's exact test and Chi square analysis. A significance level of $0.05(p=0.05)$ was used to determine the significance of associations and to report on the results.

\section{Results \\ Demographic profile}

Table 1 summarises the demographic profile of the neonatal staff in this study. The majority of respondents were from the professional nurse category $(88.68 \% ; n=47)$; females $(94.34 \%$; $n=50)$; and working in the NICU $(80.77 \% ; n=42)$. Twenty four (45.28\%) had less than 5 years' and the remaining 29 (54.62\%) 6 or more years' working experience in neonatal care. 
TABLE 1: Respondent demographics.

\begin{tabular}{llcr}
\hline Demographic & Variable & Frequency & \% \\
\hline Level of neonatal ward & NICU & 42 & 80.77 \\
& High-care & 10 & 19.23 \\
Professional qualifications & Consultant & 1 & 1.89 \\
& Registrar & 2 & 3.77 \\
& Intern & 1 & 1.89 \\
& Professional nurse & 47 & 88.68 \\
& Enrolled nurse & 2 & 3.77 \\
Work experience (years) & 0-5 years & 24 & 45.28 \\
& 6-10 years & 11 & 20.75 \\
& 11-15years & 5 & 9.43 \\
& 16-20 years & 8 & 15.09 \\
& $>21$ years & 5 & 9.43 \\
Gender & Female & 50 & 94.34 \\
& Male & 3 & 5.66 \\
\hline
\end{tabular}

NICU, neonatal intensive care unit.

\section{Objective 1: Explore current neonatal pain management strategies}

A review of the pain management interventions utilised in the study setting indicated a preference for pharmacological interventions to relieve moderate to severe procedural pain, as seen in Figure 1.

\section{Objective 2: Describe the knowledge of neonatal staff on neonatal pain}

An open-ended question allowed the respondents to write their view of what they considered neonatal pain to be. Eleven $(21.15 \%)$ defined neonatal pain either as a nonspecific behavioural response to a painful stimulus and the minority $(13.46 \% ; n=7)$ as a physiological reaction to pain. Only $3(5.77 \%)$ staff gave the whole definition of neonatal pain in terms of both behavioural and physiological response to painful stimuli. These items were included to establish respondents' experiential knowledge of neonatal pain. The item on the availability of neonatal guidelines was included to find out if a clear guideline oversees practice in neonatal wards. Sixty-four per cent of the respondents reported the absence of a written pain management guideline in the wards they worked in, whilst $36 \%$ had a written pain management guideline.

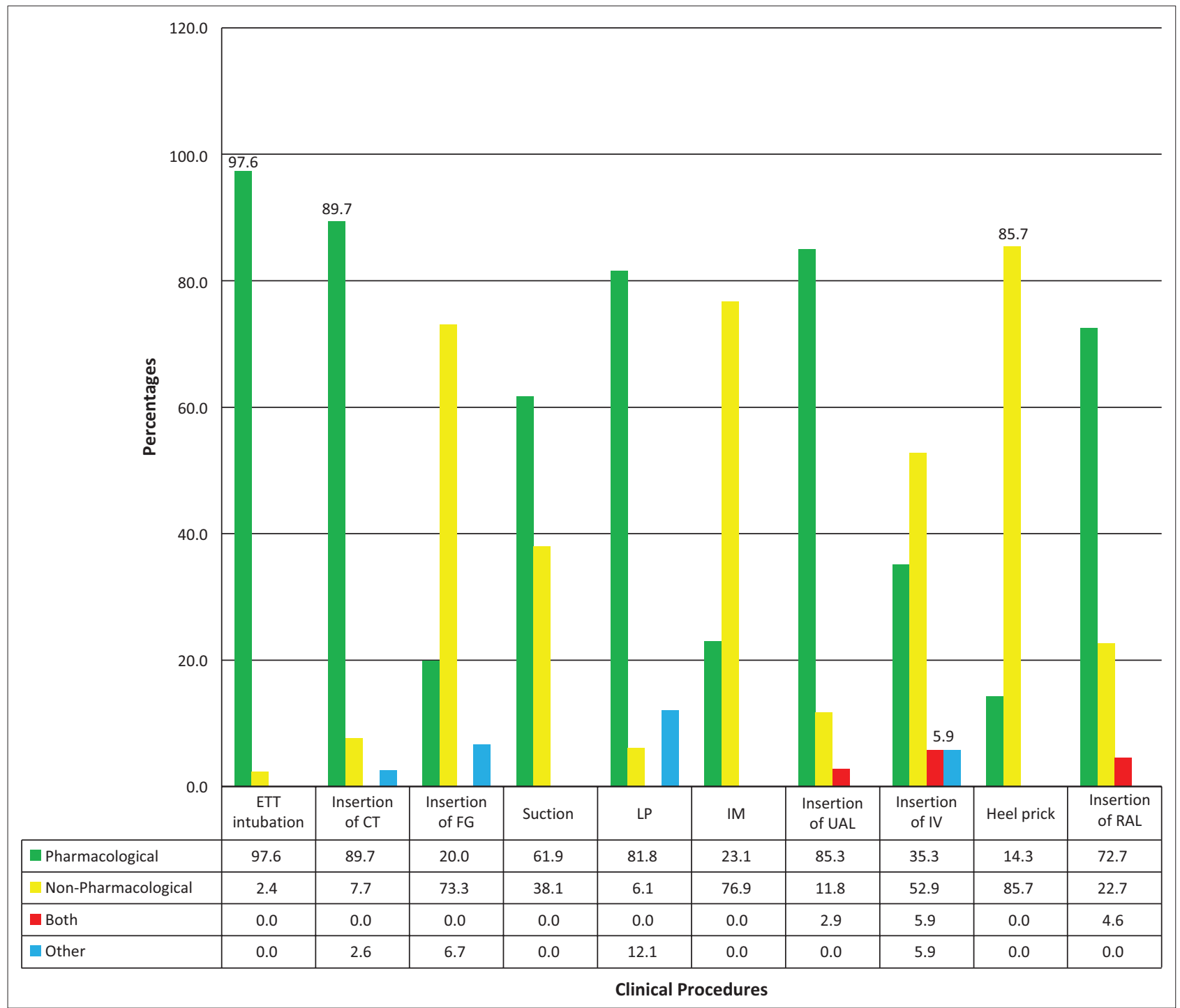

ETT, endotracheal intubation; CT, chest tube; FG, feeding tube; Suction, tracheal suctioning; LP, lumbar puncture; IM, intramuscular injection; UAL, umbilical catheter (arterial/venous); IV, peripheral intravenous line; RAL, radial arterial line.

FIGURE 1: Categories of pre-clinical procedural pain management interventions. 
Objective 3: Examine attitudes and beliefs of neonatal staff regarding neonatal pain

The measure of association between respondents' ratings of the intensity of procedural pain and the frequency of implementation of pain management interventions was calculated using Fischer's exact test. This cohort rated eight out ten procedures as severely painful and two procedures as moderately painful. A general trend that emerged from the data indicated increased implementation of pharmacological interventions with procedures rated as severely painful. Procedures rated as moderately painful received more nonpharmacological interventions.

As indicated in Table 2, a $p$-value $<0.05$ was considered statistically significant and indicated a negative association between procedural pain ratings and frequency of implementing pharmacological pain interventions. The procedural pain ratings for insertion of a nasogastric tube, lumbar puncture, heel prick, insertion of an umbilical catheter and peripheral venous cannulation would not result in increased administration of pharmacological interventions. This finding is congruent for nasogastric tube insertion; this procedure was rated as moderately painful and would be managed with non-pharmacological intervention. The findings on the other procedures raised concerns of the appropriateness of the ratings and pain management interventions. A positive finding was the respondents' report of increased frequency of pharmacological interventions to manage severe painassociated procedures and one moderately painful procedure.

\section{Ethical considerations}

Permission to conduct the study was obtained from the School of Therapeutic Sciences Research Assessor Group. Ethical approval was received from the Ethics Committee (M091047). Permission to access the neonatal wards and recruit staff was obtained from the Gauteng Department of Health, hospital chief executive officers, heads of paediatric and clinical units and unit managers. Respondents were given information letters inviting them to provide data and assuring them that refusal to be part of the study did not carry penalties.

\section{Trustworthiness \\ Validity and reliability}

In this study translational validity was established using Trochim's (2001, in DeVon et al. 2007) definition, which consists of both face and content validity. Face validity refers to the language and presentation of the tool in relation to participants' context. An expert panel consisting of five nurse educators, a paediatrician and neonatal nurse administered the Infant Pain Questionnaire for review and comment. The following changes were made based on their recommendations to ensure that the questionnaire was easy to read, understandable and applicable to the South African context: replacing the wording on insertion of peripheral intravenous catheters to intravenous lines; and formatting of the tool for readability; separation of the last three questions to specify pain relief and management pre, during and post procedure. Although the response rate was acceptable, the sample was not representative of the neonatal staff and was biased towards professional nurses.

\section{Discussion}

The professional nurse category was the major contributor to the data collected in this study $(88.68 \% ; n=47)$, whilst medical doctors comprised $7.55 \%(n=4)$ of respondents. This is consistent with the overall health staff ratio in developing countries (Naicker et al. 2009). Eighty one per cent of respondents work in the NICU and the remaining $19 \%$ in high-care wards. Currently professional nurses form the majority of the staff complement in neonatal wards, with the nurse to doctor ratio at 5:1. Allocation and distribution of nursing work between registered nurses and other categories of nurses is determined by the severity of patient illness and level of health care required, quantified as acuity (Kisorio, Schmollgruber \& Becker 2009).

In South Africa, professional nurses function under the regulations of the Scope of Practice (SOP) R2598 of 1984 (South African Nursing Council 1984a). The role of the professional nurse in pain management interventions in the neonatal care setting includes assessment of the comfort needs of the neonate, observation of patient response to clinical procedures and evaluation of how these influence patient comfort and rest. Although the SOP of a registered nurse precludes a nurse from prescribing Schedule 5 and above pharmacological pain medication (South African Nursing Council 1984b), they are expected to report pain and advocate for and suggest the prescription of pharmacological agents by a medical doctor, based on assessment of the degree of pain in the neonate. The professional nurse receives, verifies and administers the

TABLE 2: Association between procedural pain rating and pharmacological pain management implementation.

\begin{tabular}{|c|c|c|c|}
\hline Belief - frequency of pharmacological interventions & Pearson $\mathrm{Chi}^{2} \chi^{2}$ & Procedural pain ratings & Fischer's exact; $p$-value \\
\hline Endotracheal intubation & 1.9273 & 0.749 & 0.696 \\
\hline Insertion of a chest tube & 3.9675 & 0.138 & 0.292 \\
\hline Insertion of a feeding tube & 10.6022 & $0.031^{*}$ & $0.026^{*}$ \\
\hline Tracheal suctioning & 4.8845 & 0.299 & 0.418 \\
\hline Lumbar puncture & 10.2219 & $0.006^{*}$ & $0.011^{*}$ \\
\hline Intramuscular injection & 5.1571 & 0.272 & 0.169 \\
\hline Insertion of umbilical catheter & 10.2614 & $0.036^{*}$ & $0.020^{*}$ \\
\hline Insertion of a peripheral intravenous catheter & 10.2391 & $0.006^{*}$ & $0.003 *$ \\
\hline Heel prick & 14.0082 & $0.007^{*}$ & $0.005^{*}$ \\
\hline Insertion of radial arterial catheter & 5.2894 & 0.071 & 0.053 \\
\hline
\end{tabular}

${ }^{*} p \leq 0.05$ 
prescription, evaluates the effectiveness of the intervention and reports patient outcomes. The desired outcome is based on the need to enhance neonatal comfort and rest, as evidenced by reduction in the frequency of negative neonatal pain stimulus responses, such as desaturation, hypertension and bradycardia. Non-pharmacological pain management interventions fall largely within the prescriptive role of the nurse and may be implemented accordingly.

In this study most of the respondents reported there not being any available procedural guidelines; however, they described use of some appropriate pain management measures. This study did not set out to assess proficiency, but proficient nurse practitioners are described as using reflection and clinical judgement to attend appropriately to individual neonatal symptoms of pain (Benner, Tanner \& Chesla 1992).

Interdependent relationships between nurses and medical doctors form the foundation for neonatal pain management. This requires each professional to acknowledge the other's SOP, value clinical observations and collaborate in decisionmaking concerning neonatal pain management and interventions to be used. The medical doctor's role may be to prescribe, but that of the nurse is to assess and track neonatal pain, administer interventions and evaluate the effect of pain medication and other interventions.

Nurses need a foundational knowledge of neonatal pain to function in their role. An assumption made in this study is that knowledge of neonatal pain results in identification of neonatal pain and increased effective pain management. This knowledge is acquired formally through academic preparation and informally through clinical experiential learning. The scope of this knowledge covers the definition, biophysiological and behavioural aspects of neonatal pain and the various pain management interventions. Most $(n=41 ; 78.8 \%)$ respondents acknowledged that neonates experience pain more intensely than adults, and therefore had increased awareness of neonatal pain. These findings could not, however, confirm better pain management in this study group. So this finding does not concur with research results of McLaughlin et al. (1993), Porter et al. (1997), and Dodds (2003), where increased awareness of neonatal pain experience led to increased pain management.

Neonatal pain management guidelines and protocols may facilitate continued learning through provision of evidencebased best practice. Some authors report that knowledge is acquired, transferred into practice and retained (McKechnie \& Levene 2008; Spence et al. 2010). However, in this study 32 respondents reported the absence of neonatal pain management guidelines in their practice. This raised concern around the consistency and adequacy of information and evidence-based guidelines for neonatal pain management. In the local context the respondents' opinions on neonatal pain did not present a holistic view of the phenomenon and its defining characteristics.
Despite this neonatal staff showed a positive attitude towards neonatal pain management, as indicated by the results from testing the strength of the association between pain ratings and implementation of pharmacological interventions (see Table 3). With increased severity of pain, professional nurse respondents believed that the frequency of pharmacological pain management interventions should be increased. Moreover the respondents' ratings of procedural pain concur with empirical evidence on the painfulness of these procedures (Anand et al. 1999; Granau et al. 2006; Carbajal et al. 2008; Johnston et al. 2010).

It is clear that the choice of pain management intervention in this setting is largely pharmacological. This is consistent with international standards for the adequate pain management of moderate to severe pain (Anand 2007; Lago et al. 2009). Nursing studies addressing neonatal pain management support the implementation of non-pharmacological interventions, particularly with prevention and alleviation of neonatal procedural pain (Halimaa et al. 2001; Spence et al. 2010; Johnston et al. 2010). The nurses in this study reported implementing swaddling and non-nutritive sucking (without oral sucrose) as preferred methods of non-pharmacological pain management intervention. Taddio et al. (2008) proved the effectiveness of this intervention, and addressed concerns related to the effect of oral sucrose on neonatal glucose homeostasis, finding that low doses did not increase the neonates' blood glucose.

\section{Limitations of the study}

The response rate was much lower than anticipated, and lower than the 150 required to attain a 95\% confidence interval. Whilst the response rate of $35 \%$ is low, it is well recognised that the response rate to questionnaires is often low, and there are authors that indicate that this is sufficient (Baruch \& Holtom 2008). The small sample size means that these findings cannot be generalised to describe neonatal pain management practice in all academic hospitals in Gauteng and the factors affecting implementation of interventions.

Collapsing of data for comparative analysis resulted in reduction of specificity on reporting of the findings, for example the classification of pharmacological agents or pain relief measures.

Inclusion of a record review to give an accurate reflection of current practice may have given an in-depth description of neonatal pain management practice in this study and increased the validity of the findings. This was beyond the scope of this report.

The dearth of South African literature resulted in a biased literature review, which favoured international practice.

\section{Recommendations}

Neonatal pain management needs to be standardised, monitored and evaluated in these settings. The adoption of a 
neonatal pain management is recommended. A neonatal staff multidisciplinary team should be established to implement and validate the chosen guideline. This will also serve to maintain and enhance the positive attitude that the staff have towards neonatal pain management, as staff are empowered to practice independently using a consensual evidence-based guideline. This guideline will also provide nurses with a platform to implement increased safe non-pharmacological interventions with confidence based on current evidence.

The academic hospitals in this study are part of the ChildFriendly Hospitals Initiative, where pain management is one of the principles to provide safe and effective child-centred care. Neonatal wards thus have an obligation to ensure continuous education on pain management through in-service training.

\section{Conclusion}

A concern about neonatal pain management in clinical practice motivated this study. An empirical enquiry into this sensitive subject resulted in the choice of a survey as the study design. Analysis of data collected from the neonatal staff working in two academic hospitals in Gauteng confirmed the observations made by the researcher that neonatal pain, though assessed and managed, is not standardised and may be subjective according to neonatal staff's experience with neonatal pain and its management. Neonatal staff acknowledge that neonates experience pain, and manage neonatal pain in the absence of a guideline. The respondents favoured pharmacological interventions, even though this lies beyond the prescriptive scope of the nurses who were the main contributors to this study. Non-pharmacological interventions are used minimally in the study settings; use of these could be increased by the implementation of guidelines based on empirical evidence confirming their effectiveness when used appropriately. The interdependent relationship between nurses and doctors requires them to work in collaboration in order to improve neonatal pain management.

Increased interest in neonatal pain management, especially the harmful effects of unrelieved pain on the physical, psychological and emotional development of the neonate, leads to the conviction that quality neonatal care must begin with adequate assessment and management of neonatal pain. A best practice clinical guideline of neonatal pain management is required to facilitate this process.

\section{Acknowledgements Competing interests}

The authors declare that they have no financial or personal relationship(s) that may have inappropriately influenced them in writing this article.

\section{Authors' contributions}

This work was conducted and submitted as the requirement for completion of an MSc in Child Nursing degree by research report. S.L.T.K. (University of the Witwatersrand) is the principal researcher and author of this article, and A.A.T. (Child Nurse Consultant) supervised the research.

\section{References}

Abdulkader, H.M., Freer, Y., Garry, E.M., Fleetwood-Walker, S.M. \& McIntosh, N., 2008 , 'Prematurity and neonatal noxious events exert lasting effects on infant pain behaviour', Early Human Development 84, 351-355. http://dx.doi.org/10.1016/j. earlhumdev.2007.09.018

American Academy of Pediatrics \& Canadian Paediatric Society, 2000, 'Prevention and management of Pain and Stress in the neonate', Paediatrics 105, 454-461. http:// dx.doi.org/10.1542/peds.105.2.454

Anand, K.J.S. \& Hickey, P.R., 1987, 'Pain and its effects in the human neonate and fetus', New England Journal of Medicine 19, 1321-1329. http://dx.doi.org/10.1056/ NEJM198711193172105

Anand, K.J.S., Coskun, V., Thrivikraman, K. V., Nemeroff, C.B. \& Plotsky, P.M. 1999, 'Long-term behavioural effects of repetitive pain in neonatal rat pups', Physiology \& Behavior 66(4), 627-637. http://dx.doi.org/10.1016/S00319384(98)00338-2

Anand, K.J.S. \& International Evidence-Based Group for Neonatal Pain, 2001, 'Consensus Statement for the Prevention and Management of Pain in the Newborn', Archives of Pediatric and Adolescent Medicine 155, 173-180, viewed 05 October 2012, from http://archpedi.jamanetwork.com/journal.aspx.

Anand, K.J.S., Hall, R.W., Desai, N.S., Shephard, B., Bergqvist, L.L., Young, T.E. et al., 2004, 'Effects of morphine analgesia in ventilated preterm neonates: Primary
outcomes from the NEOPAIN randomised trial', Lancet 363, 1673-1682. http:// dx.doi.org/10.1016/S0140-6736(04)16251-X

Anand, K.J.S., 2007, 'Pharmacological approaches to management of pain in the neonatal intensive care unit', Journal of Perinatology 27, S4-S11. http://dx.doi. org/10.1038/sj.jp.7211712

Anand, K.J.S. \& Hall, R.W., 2008, 'Love, pain and intensive care', Paediatrics 121 825-827, viewed 8 October 2012, from http://www.pediatrics.org/cgi/content/ full/121/4/825.

Andersen, R.D., Greve-Isdahl, M. \& Jylli, L., 2007, 'The opinions of clinical staff regarding neonatal procedural pain in two Norwegian neonatal intensive care units', Acto Pediatrica 96, 1000-1003. http://dx.doi.org/10.1111/j.1651-2227.2007.00190.x

Ballweg, D., 2007, 'Neonatal and paediatric pain management: Standards and application', Paediatrics and Child Health 17(S1), S61-S66.

Baruch, Y. \& Holtom, B.C., 2008, 'Survey response rate levels and tends in organizational research', Human Relations 61, 1139-1160. http://dx.doi. org/10.1177/0018726708094863

Belliene, C.V., lantorno, L., Perrone, S., Rodriguez, A., Longini, M., Capitani, S. \& Buonocore, G., 2009, 'Even routine painful procedures can be harmful for the newborn', Pain 147, 128-131. http://dx.doi.org/10.1016/j.pain.2009.08.025

Bellini, S. \& Damato, E.G., 2009, 'Nurses' knowledge, attitude/beliefs and care practices concerning do not resuscitate status for hospitalized neonates', Journa of Obstetrics, Gynecological \& Neonatal Nursing 38(2), 195-220. http://dx.doi. org/10.1111/j.1552-6909.2009.01009.x

Benner, P., Tanner, C. \& Chesla, C., 1992, 'From beginner to expert: Gaining a differentiated clinical world in critical care nursing', Advances in Nursing Science 14(3), 13-28, viewed 20 April 2009, from http://www.sciencedirect.com/science/ article/pii/S1524904209000538

Burns, N. \& Grove, S.K., 2005, The Practice of Nursing Research, Conduct Critique and utilisation, W.B. Saunders, Philadelphia.

Carbajal, R., Rousset, A., Danan C., Coquery, S., Nolent, P., Ducrocq, S., Saizou, C. et al., 2008 , 'Epidemiology and treatment of painful procedures in neonates in intensive care units', Journal of the American Medical Association 300(1), 60-70. http:// dx.doi.org/10.1001/jama.300.1.60

DeVon, H.A., Block, M.E., Moyle-Wright, P., Ernst, D.M., Hayden, S.J., Lazzara, D.J., Savoy, S.M. \& Kostas-Polston, E., 2007, 'A psychometric toolbox for testing validity and reliability', Journal of Nursing Scholarship 39(2), 155-164. http://dx.doi. org/10.1111/j.1547-5069.2007.00161.x

Dodds, E., 2003, 'Neonatal procedural pain: A survey of nursing staff', Paediatric Nursing 15(5), 18-21. http://dx.doi.org/10.7748/paed2003.06.15.5.18.c857

Evan, J.C., 2001, 'Physiology of acute pain in preterm infants', Newborn and Infant Nursing Reviews 1(2), 75-84. http://dx.doi.org/10.1053/nbin.2001.25302

Fitzgerald, M. \& Anand, K.J.S., 1993, 'Developmental neuroanatomy and neurophysiology of pain', in N.L. Schechter, C.B. Berde \& M. Yaster (eds.), Pain in Infants, Children, and Adolescents, pp. 11-32, Williams \& Wilkens, Baltimore, MD.

Gradin, M. \& Eriksson, M., for the NeoOpioid investigators group, 2010, 'Neonatal pain assessment in Sweden - a fifteen year follow-up', ActaPaediatrica 100, 204-208.

Granau, R.E., Holsti, L. \& Peters, J.W.B., 2006, 'Long-term consequences of pain in human neonates', Seminars in Fetal Neonatal Medicine 11, 268-275. http:// dx.doi.org/10.1016/j.siny.2006.02.007

Halimaa, S-L., Vehviläinen-Julkunen, K. \& Heinonen, K., 2001, 'Knowledge, assessment and management of pain related to nursing procedures used with premature babies: Questionnaire study of caregivers', International Journal of Nursing Practice 7, 422-430. http://dx.doi.org/10.1046/j.1440-172X.2001.00322.x

Hummel, P. \& Puchalski, M., 2001, 'Assessment and management of pain in infancy', Newborn and Infant Nursing Reviews 1(2), 114-121. http://dx.doi.org/10.1053/ nbin.2001.25104 
Johnston, C.C., Stevens, B., Yang, F. \& Horton, L., 1995, 'Differential response to pain by very premature neonates', Pain 61, 471-479. http://dx.doi.org/10.1016/0304 by very premature
3959(94)00213-X

Johnston, C.C., Anand, M.F. \& Campbell-Yeo, M. for the International Association for the Study of Pain, 2010, 'Pain in neonates is different', Pain 152, S65-S7. http://dx.doi.org/10.1016/j.pain.2010.10.008

Kisorio, L., Schmollgruber, S. \& Becker, P., 2009, Validity and reliability of the simplified therapeutic intervention scoring system in intensive care units of a public sector hospital in Johannesburg', South African Journal of Critical Care 25(2), 36-43.

Kolchaba, K.Y., 1995, 'Comfort as process and product, merged in holisticnursing art', Journal of Holistic Nursing 13(2), 117-131. http://dx.doi. org/10.1177/089801019501300203

Lago, P., Garetti, E., Merazzi, D., Pieragostini, L., Ancora, G., Pirelli, A. \& Belliene, C.V. on behalf of the Pain Study Group of the Italian Society, 2009, 'Guideline for procedural pain in the newborn', ActaPaediatrica 98, 932-939, viewed 05 Octobe 2012, from http://onlinelibrary.wiley.com/doi/10.1111/j.16512227.2009.01291. $\mathrm{x} /$ full

LoBiondo-Wood, G. \& Haber, J., 2006, Nursing Research: Methods and Critical Appraisal for Evidence-Based Practice, 6th edn., Missouri, Mosby, Elsevier.

Maree K., 2009, First Steps in Research, Van Schaik, Pretoria.

McKechnie, L. \& Levene, M., 2008, 'Procedural pain guidelines for the newborn in the United Kingdom', Journal of Perinatology 28(2), 107-111. http://dx.doi. org/10.1038/sj.jp.7211822

McLaughlin, C.R., Hull, J.G., Edwards, W.H. et al., 1993, 'Neonatal pain: A comprehensive survey of attitudes and practice', Journal of Pain and Symptom Management 8(1), 7-16. http://dx.doi.org/10.1016/0885-3924(93)90114-B

Merskey, H., Alber-Fessard, D.G., Bonica, J.J, Carmon, A., Dubner, R., Kerrf, W.L. et al., and the International Association for the Study of Pain, 1979, 'Pain terms: A list with definitions and notes on usage: recommended by International Association on Pain Management Subcommittee on Taxonomy', Pain 6, 249-252.

Naicker, S., Plange-Rhule, J., Tutt, R.C. \& Eastwood, J.B., 2009, 'Shortage of healthcare workers in developing countries: Africa', Ethnicity and Disease 19(1, Suppl 1) $60-64$.
Porter, F.L., Wolf, C.M., Gold, J., Lotsoff, B.S. \& Miller, A.B., 1997, 'Pain and pain management in newborn infants: A survey of physicians and nurses', Paediatrics 100(4), 626-633. http://dx.doi.org/10.1542/peds.100.4.626

Rouzan, I.A., 2001, 'An analysis of research and clinical practice in neonatal pain management', Journal of the American Academy of Nurse Practitioners 13(2), 57-60. http://dx.doi.org/10.1111/j.1745-7599.2001.tb00218.x

Sharek, P.J., Powers, R., Koehn, A. \& Kanwaljeet, J.S., 2006, 'Evaluation and development of potentially better practices to improve pain management of neonates', Paediatrics 118, S78-S86. http://dx.doi.org/10.1542/peds. 2006-0913D

Simons, S.H.P., Van Dijk, M., Anand, K.J.S. et al., 2003, 'Do we still hurt newborn babies? A prospective study of procedural pain and analgesia in neonates' Archives of Pediatrics and Adolescent Medicine 157, 1058-1064. http://dx.doi. org/10.1001/archpedi.157.11.1058

South African Nursing Council, 1984a, Government Notice Regulation 2598 as amended, Regulation related to the scope of practice of person registered or amended, Regulation related to the scope of practice of person registered
enrolled under the Nursing Act, 2005, Pretoria, South African Nursing Council.

South African Nursing Council, 1984b, Government Notice No. R. 2418, Regulations relating to the keeping, supply, administering or prescribing of medicines by registered nurses, Pretoria, South African Nursing Council.

Spence, K., Henderson-Smart, D., New, K., Evans, C., Whitelaw, J. \& Woolnough, R. for the Australian and New Zealand Neonatal Network, 2010, 'Evidencedbased clinical practice guideline for management of newborn pain', Journal of based clinical practice guideline for management of newborn pain', Journal of
Paediatrics and Child Health 46, 184-192. http://dx.doi.org/10.1111/j.14401754.2009.01659.x

Taddio, A., Shah, V., Hancock, R, Smith, R.W., Stephens, D., Atenafu, E., Beyene, J. Koren, G., Stevens, B. \& Katz, J., 2008, 'Effectiveness of sucrose analgesia in Koren, G., Stevens, B. \& Katz, J., 2008, 'Effectiveness of sucrose analgesia in
newborns undergoing painful medical procedures', Canadian Medical Association newborns undergoing painful medical procedures', Canadian M
Journal 179(1), 37-43. http://dx.doi.org/10.1503/cmaj.071734

Urso, A.M., 2007, 'The reality of neonatal pain and the resulting effects', Journal of Neonatal Nursing 13, 236-238. http://dx.doi.org/10.1016/j.jnn.2007.09.006

Walker, S.M. \& Howard, F.R., 2002, 'Neonatal pain', Pain Review 9, 69-79. http:// dx.doi.org/10.1191/0968130202 